\title{
Attitudes of Asian medical students towards smoking
}

\author{
S Fayyaz Hussain, Imran Moid, Javaid A Khan
}

\begin{abstract}
Background - There have been numerous studies on smoking habits among young adults in developed countries. Similar data from developing countries are scanty. Methods - A survey of medical students from one of the medical colleges in Pakistan assessed their smoking habits and attitudes towards smoking. In June 1993 a coded survey questionnaire was sent to each medical student at The Aga Khan Medical University in Karachi requesting data on their smoking habits, their attitudes towards smoking in various areas of the hospital, and their views about passive smoking and tobacco publicity.

Results - Of 324 medical students, 89\% responded of whom $11 \%$ were current smokers. The incidence of smoking was greater among male students than females $(17 \%$ versus $4 \%)$. The average age of initiation of smoking was 17 years and the major influence was friends. There was an increased awareness of harmful effects of smoking among medical students. Almost all felt that passive smoking was injurious to health.

Conclusion - The prevalence of current smokers among Asian medical students was found to be $11 \%$. Females smoked less than their male counterparts. There has been an increased awareness of the hazards of passive smoking among the medical students and most were in favour of legislative actions to discourage tobacco advertising.
\end{abstract}

(Thorax 1995;50:996-997)

Keywords: smoking, young adults, Pakistan.

Cigarette smoking is one of the commonest preventable causes of death, ${ }^{1}$ with 431000 people dying of smoking-related diseases in the European community each year. ${ }^{2}$ Although the incidence of smoking is on the decline in the west, an increase has been noticed among young adults and adolescents; five out of six adult smokers begin smoking by the age of $16 .^{3}$

Little information is available on the incidence of smoking in the general population in Pakistan, or on attitudes of young adults towards smoking. Taking medical students of Aga Khan University as a group representing young adults and health professionals, we carried out a smoking survey to ascertain the prevalence of smoking among them and to determine their smoking habits and attitudes towards smoking.
Methods

All medical students enrolled at the University on 1 June 1993 received a coded survey questionnaire which sought information about age, sex, smoking habits, and parental smoking status. The students were also asked if smoking should be permitted in various areas of the hospital, and whether there should be 24 hour access to smoking areas for doctors, patients, and visitors. Smokers were asked about factors influencing the initiation of the habit, the age of onset of smoking, and whether they now wished to quit. The views of the medical students about passive smoking and tobacco publicity were also determined.

Medical students who had not responded the first time were sent a second questionnaire two months later. All questionnaires returned by the end of December 1993 were analysed. Statistical significance was tested by Fisher's exact test.

\section{Results}

Of 324 medical students questioned, 289 $(89 \%)$ responded of which $55 \%$ were male. Among respondents $11 \%$ were current smokers, $84 \%$ non-smokers, and $5 \%$ exsmokers. Non-smokers were defined as those who had never smoked, ex-smokers as those who had smoked in the past but had now stopped, and current smokers as those who continued to smoke any amount of tobacco either regularly or occasionally. The incidence of smoking was significantly higher in male students $(17 \%$ versus $4 \%, p<0.001)$. At least one of the parents of $42 \%$ of the medical students was a smoker. The incidence of smoking among parents was higher among tobacco using students ( $47 \%$ versus $40 \%$ ), but this difference was not statistically significant.

Nearly two thirds (61\%) of respondents thought smoking should be banned completely in hospital. Most medical students felt that smoking should be banned in laboratories $(97 \%)$, wards $(97 \%)$, and cafeterias $(87 \%)$; about three quarters thought that it should not be allowed in offices $(77 \%)$, corridors $(76 \%)$, waiting areas $(75 \%)$, and toilets $(75 \%)$. However, $36 \%$ felt that smoking should be allowed in a lounge.

Most respondents (92\%) wanted to deny visitors access to smoking, whereas $24 \%$ and $68 \%$, respectively, thought this facility should be available to patients and staff. Virtually everyone $(98 \%)$ agreed that passive smoking is injurious to health. When asked about tobacco publicity, again most of the students thought that it should be discouraged on television 
(98\%), in newspapers (79\%), and on sports coverage $(67 \%)$.

Of the smokers, the average number of cigarettes smoked daily was $8 \cdot 5$, with $53 \%$ smoking 1-5 cigarettes daily. The average age of starting smoking was 17 years with $88 \%$ having started before their 21 st birthday. The major influence for initiation was their friends $(66 \%)$. Half of the smokers wished to quit smoking, one third were unsure about it, and $15 \%$ did not want to give up the habit.

\section{Discussion}

Medical students were made the focus of this survey because they constitute a group of young adults which has shown an increasing prevalence for smoking in the west, ${ }^{1}$ and also they are potential health professionals and their attitudes and views could affect future policies.

The response rate of $89 \%$ was encouraging. The prevalence of current smokers at $11 \%$ was lower than among European medical students $(21 \%)^{4}$ and among other Asian medical students (up to $24 \%$ in the final year). ${ }^{5}$ There has been an increased awareness of the harmful effects of smoking on health among medical students. Almost all (98\%) students, irrespective of sex and smoking habit, felt that even passive smoking was injurious to health. This was in sharp contrast to the finding in a previous Asian study where up to $40 \%$ of smoking medical students denied knowledge of the harmful effects of tobacco.

The average age of smoking onset in our study was 17 years. This has not been studied in other reports on smoking from Asia, but studies from Europe have shown that a higher percentage of smokers today start smoking at an earlier age, the increase being more marked among women. ${ }^{6}$

1 Vickers $\mathrm{A}$. Why cigarette advertising should be banned. $B M \mathcal{F}$ 1992;3:93-4.

2 European Bureau for Action on Smoking Prevention. Newsletter 1991;13:10.

3 Office of Population Censuses and Surveys. General Household Survey, 1988. London: HMSO, 1990.

4 Tessier JF, Freour P, Crofton J, Kombou L. Smoking habits and attitudes of medical students towards smoking and anti smoking campaigns in fourteen European countries. Eur f Epidemiol 1989;5:311-21.

5 Tessier JF, Freour P, Belougne D, Crofton J. Smoking habits and attitudes of medical students towards smoking and anti smoking campaigns in nine Asian countries. Int $\mathcal{f}$ Epidemiol 1992;21:298-304.

6 Osler M. Smoking habits in Denmark from 1953 to 1991 . A comparative analysis of results from three nationwide health surveys among adult Danes in 1953-1954, 1986-1987 and 1990-1991. Int f Epidemiol 1992;21:862-71. 